\title{
Inhibition of Bone Marrow Stem Cell Growth In Vitro by Methylmalonic Acid: a Mechanism for Pancytopenia in a Patient with Methylmalonic Acidemia
}

\author{
SUSUMU INOUE, ${ }^{(2)}$ INGEBORG KRIEGER, ASHOK SARNAIK, YADDANAPUDI RAVINDRANATH, \\ MICHAEL FRACASSA, AND MARK J. OTTENBREIT \\ The Department of Pediatrics, Wayne State University School of Medicine, Children's Hospital of Michigan. The \\ Child Research Center of Michigan, Detroit, Michigan, USA
}

\begin{abstract}
Summary
A 7-week-old infant with methylmalonic acidemia had pancytopenia and hypoplastic bone marrow. The patient responded to large doses of vitamin B12 treatment, and within $3 \mathrm{wk}$, the blood counts and bone marrow cellularity returned to normal. To understand the mechanism of marrow depression in this infant, we examined the effect of the patient's plasma and methylmalonic acid itself on the in vitro growth of bone marrow-committed stem cells. The patient's plasma obtained before B12 treatment completely inhibited the marrow cell growth, whereas the posttreat ment plasma showed no inhibition. Methylmalonic acid when added to the culture dishes in concentrations comparable to those reported in plasma of methylmalonic acidemia patients, inhibited growth of marrow stem cells in a concentration-dependent fashion. On the other hand, 16 to $18 \mathrm{hr}$ incubation of cells in the same concentration of methylmalonic acid did not affect the recovery or viability of the cells. The observations suggest that methylmalonic acid is inhibitory to the proliferation of marrow stem cells. The mechanism of inhibition is yet to be elucidated.
\end{abstract}

\section{Speculation}

MMA at a concentration comparable to that reported in patients with methylmalonic acidemia inhibited in vitro growth of marrow hemopoietic cells, but overnight incubation of the cells in MMA at the same concentration did not reduce the number of viable cells determined by the trypan blue dye exclusion test. It appears, therefore, that MMA within the range of concentration tested is not immediately cytotoxic. Its inhibitory action thus seems to require longer cell contact hours than the 16 to $18 \mathrm{hr}$ we used, and it may be directed against rapidly proliferating cell population. The potential mechanisms of inhibition are unknown and more work is needed to understand the interaction of MMA with hemopoietic cells.

Leukopenia and thrombopenia are known to occur in the patients with ketotic hyperglycinemias such as methylmalonic (MMA-emia), propionic, or isovaleric acidemia (18), but the pathogenesis of the cytopenias is poorly understood. Recently, we had an opportunity to study the hematological aspect of methylmalonic acidemia in an infant with this disorder who presented with bone marrow hypoplasia and ketoacidosis. The association of MMA-emia with pancytopenia due to depressed marrow hemopoiesis has not been reported. Our studies using recently popularzed in vitro marrow cell culture technique helped our understanding of hematologic problems in this patient.

\section{DESCRIPTION OF A CASE}

A 7-wk-old infant was admitted to Children's Hospital of Michigan because of vomiting, dehydration, and listlessness that had started at 3 wk of age. The laboratory studies revealed metabolic acidosis and pancytopenia (hemoglobin, $6.7 \mathrm{~g} / \mathrm{dl}$; white blood cell count, $2500 / \mathrm{mm}^{2}$; neutrophil, $950 / \mathrm{mm}^{3}$; platelets, 28 $\times 10^{3} / \mathrm{mm}^{3}$; and reticulocytes, $0.1 \%$ ). A bone marrow examination on the fourth hospital day showed marked hypocellularity with virtual absence of mature myeloid and erythroid elements and paucity of megakaryocytes. There was no megaloblastic change. Mast cells were not observed. Some of the early normoblasts and hemocytoblast-like cells showed cytoplasmic vacuolation. On the fifth hospital day, a diagnosis of MMA-emia was made based on the following laboratory data: urinary methylmalonic acid (MMA), $39.9 \mathrm{mg} / \mathrm{mg}$ of creatinine; plasma lactate, $39.3 \mathrm{mg} / \mathrm{ml}$; pyruvate, $1.89 \mathrm{mg} / \mathrm{dl}$; ammonia, $0.6 \mu \mathrm{g} / \mathrm{dl}$; glycine, $66 \mu \mathrm{moles} / \mathrm{dl}$ (normal, $17.3 \pm 4.5$ ); and methionine, $1.9 \mu$ moles/dl (normal, 1.52 \pm 0.48 ). All other plasma and urine amino acids, including homocystine, were normal. Urinary propionic acid was undetectable. Treatment with vitamin B12, $200 \mu \mathrm{g}$ IM twice daily, was started, and after 2 days of therapy, the child's clinical status improved markedly, and there was some improvement in the marrow cellularity although it was still hypoplastic. After 2 wk of continuous B 12 administration, all hemograms and marrow cellularity became normal. The vacuolated cells were no longer present in the marrow. Sequential blood counts in relations to vitamin B 12 therapy is shown in Figure 1. Urinary MMA decreased to $5.2 \mathrm{mg} / \mathrm{mg}$ creatinine at the time of discharge.

\section{METHOD}

Sterile plasma was obtained from the patient on three occasions (plasma 1 before B 12 therapy, plasmas 2 and 3 on the 10 th and 15 th posttreatment days, respectively) (Fig. 1). A control plasma sample was obtained from one of us (Dr. Inoue). The plasma was mixed with marrow cells for culture as described below.

Bone marrow cells were aspirated from the patient on two different occasions (one before B 12 therapy and the other on the 15 th posttreatment day). Each aspirate was divided into two aliquots. One was used for cytologic examination, and the other was heparinized for culture purposes. "Control" marrows were obtained from patients with acute lymphoblastic leukemia in complete remission. Some of the controls were long-term survivors and were not receiving any antileukemia therapy. All marrow aspirates were done after a proper consent form explaining a research use of a part of the specimen was signed. The research protocol had been approved by the Children's Hospital Institutional Review Board, which has an approved general assurance with requirements of the Code of Federal Regulations on Protection of Human Subjects.

MMA was purchased from Sigma Chemical Co. (St. Louis, $\mathrm{MO}$ ), and was dissolved in $\alpha$ medium. The final $\mathrm{pH}$ was adjusted to 7.3 by addition of $7 \mathrm{~N} \mathrm{NaOH}$. The MMA solution was diluted $\alpha$ medium to a final concentration of $70,35,17.5,8.75 \mathrm{mg} / \mathrm{dl}$, respectively. 


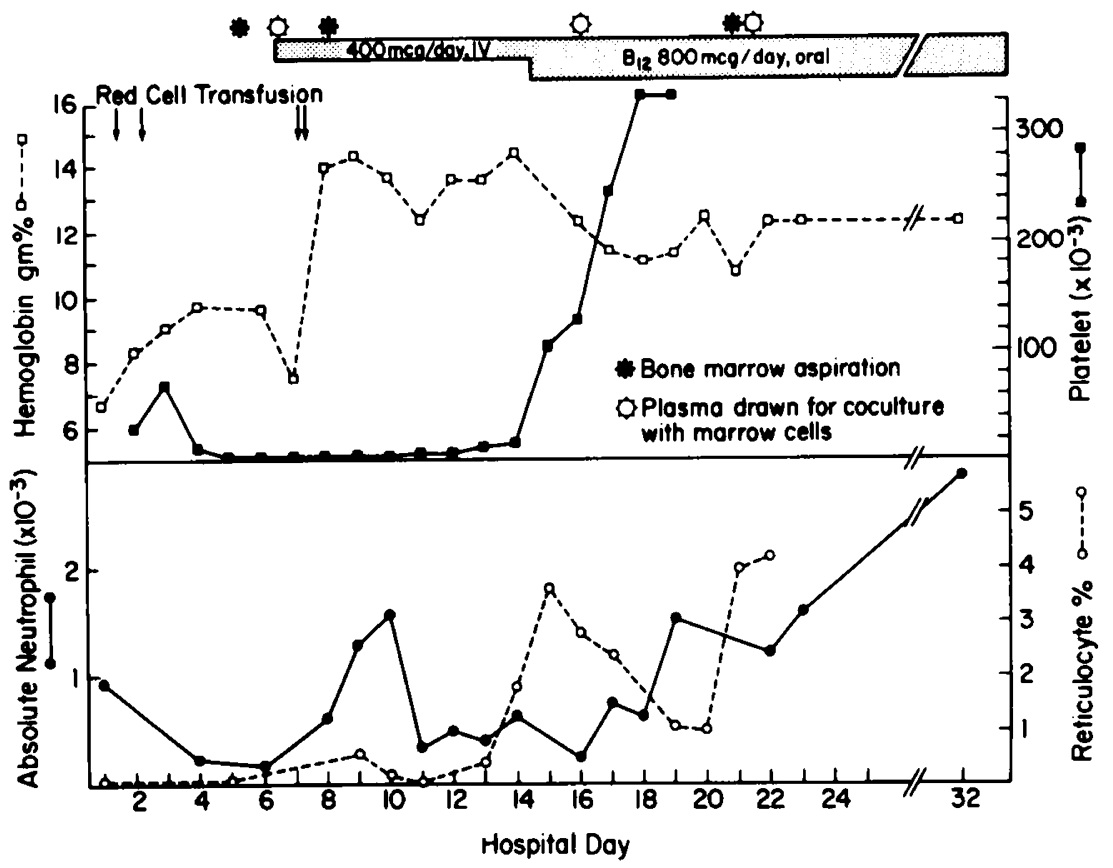

Fig. 1. Sequential change in blood counts in relation to B 12 therapy. The first and the third bone marrows were cultured in vitro to enumerate marrow stem cells.

Marrow cells were cultured according to the method previously published (10). Briefly, for the growth of CFU-C-derived colonies (macrophage-granulocyte colonies), $2 \times 10^{4}$ marrow cells were mixed with $1 \mathrm{ml}$ of culture media consisting of $0.2 \mathrm{ml}$ fetal bovine serum (FBS), $0.2 \mathrm{ml}$ fibroblast-conditioned medium containing colony-stimulating factors, $0.2 \mathrm{ml} \alpha$ medium, and $0.4 \mathrm{ml}$ of $2.4 \%$ methylcellulose and cultured in a $35 \times 10 \mathrm{~mm}$ Lux Petri dish at 35 to $36^{\circ} \mathrm{C}$ with $5 \% \mathrm{CO}_{2}$ in air. In some experiments, one-half of the FBS $(0.1 \mathrm{ml})$ was replaced by an equal volume of patient or control plasma. To examine the effect of MMA, $\alpha$ medium was partially or totally replaced by a solution of MMA in $\alpha$ medium. Colonies, an aggregate of 20 or more cells, were scored at day 6 and again on days 10 to 12 of culture. For the growth of CFU-Eand BFU-E-derivated erythroid colony growth, $5 \times 10^{4}$ marrow cells were mixed with $1 \mathrm{ml}$ of culture media consisting of $0.3 \mathrm{ml}$ FBS, $0.1 \mathrm{ml}$ of sheep step III erythropoietin containing 2 IU (Connaught Lab, Willowdale, Ontario, Canada), $0.1 \mathrm{ml}$ of $10 \%$ bovine serum albumin (Cohn fraction V.; Sigma Chemical Co.), $0.1 \mathrm{ml}$ of $\alpha$ media, and $0.4 \mathrm{ml}$ of $2.4 \%$ methylcellulose. In some experiments, one-half of the FBS volume $(0.15 \mathrm{ml})$ was replaced by an equal volume of either patient or control plasma. Erythroid colonies formed by mature committed erythroid precursor cells (CFU-E) were scored at days 6 to 9 of culture, and erythroid bursts formed by relatively immature precursors (BFU-E) (1) were scored at days 14 to 16 of culture. All cultures were done in duplicate or quadruplicate. To examine whether MMA is directly cytotoxic to cells, bone marrow cells from control patients (two patients) or Ficoll-Hypaque-separated peripheral blood cells from a patient with sickle cell anemia were incubated at a $70 \mathrm{mg} / \mathrm{dl}$ concentration of MMA in $\alpha$ medium and FBS for 16 to $18 \mathrm{hr}$. The total cell count and cell viability by trypan blue dye exclusion were then compared with simultaneously incubated cells in $\alpha$ medium and FBS only.

\section{RESULTS}

The number of CFU-C derived macrophage-granulocyte colonies and CFU-E and BFU-E derived erythroid colonies formed by the patient's own marrow cells are shown in Table 1 . The most striking finding was the absence of CFU-E derived colonies in the patient's pretreatment marrow, although both CFU-C- and BFU$\mathrm{E}$-derived colonies were also reduced in number as compared to control. In contrast, the posttreatment marrow showed a marked
Table 1. Number of CFU-C-, CFU-E-, and BFU-E-derived colonies (patient's own marrow cells)

\begin{tabular}{lccc}
\hline & $\begin{array}{c}\text { Before } \\
\text { B12 Rx }\end{array}$ & $\begin{array}{c}\text { After 13 days of } \\
\text { B12 Rx }\end{array}$ & Control $^{1}$ \\
\hline CFU-C $/ 2 \times 10^{4}$ & $30 \pm 1$ & 59 & $78.8 \pm 44.6$ \\
CFS-E $5 \times 10^{4}$ & 0 & 83 & $17.5 \pm 15.5$ \\
BFU-E $/ 5 \times 10^{4}$ & 23 & 84 & $32.7 \pm 20.8$ \\
\hline
\end{tabular}

' CFU-C control obtained from culture of 30 specimens from acute lymphoblastic leukemia survivors off chemotherapy. CFU-E and BFU-E control obtained from culture of seven specimens from acute lymphoblastic leukemia survivors off chemotherapy.

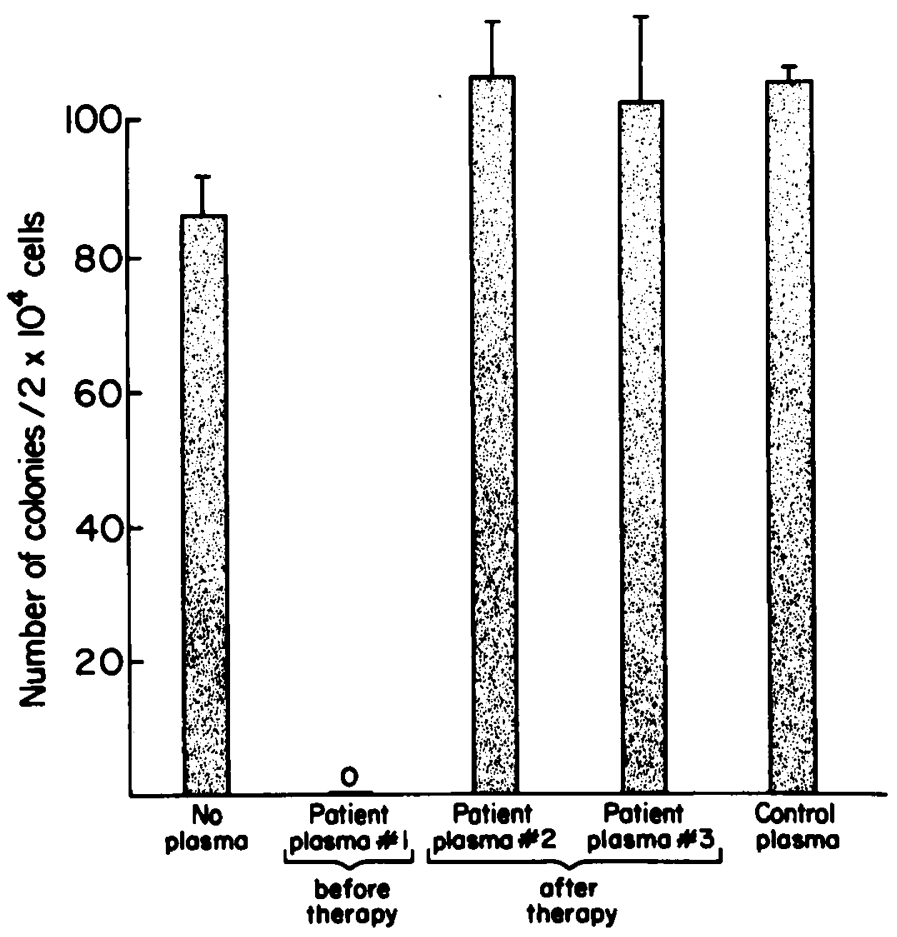

Fig. 2. Effect of patient plasma on the growth of CFU-C-derived colonies. Each plasma was cultured at a $10 \%$ concentration with control marrow cells. 
Table 2. Effects of patient's plasma (before B12) on colony growth

\begin{tabular}{clccc}
\hline Tested on & & $\begin{array}{c}\text { No } \\
\text { plasma }\end{array}$ & $\begin{array}{c}\text { Patient } \\
\text { plasma }\end{array}$ & $\begin{array}{c}\text { Control } \\
\text { plasma }\end{array}$ \\
\hline $\begin{array}{c}\text { Patient marrow } \\
\text { (before B12) }\end{array}$ & CFU-C/2 $\times 10^{4}$ & $30 \pm 1$ & 0 & $90 \pm 5$ \\
& CFU-E/5 $\times 10^{4}$ & 0 & 0 & 4 \\
& BFU-E/5 $1 \times 110^{4}$ & 23 & 0 & 15 \\
& & & & \\
Control marrow & CFU-C $/ 2 \times 10^{4}$ & $77 \pm 8$ & 0 & $96 \pm 4$ \\
& CFU-E/5 $\times 10^{4}$ & 12 & 1 & 13 \\
& BFU-E/5 $\times 10^{4}$ & 44 & 0 & 49 \\
\hline
\end{tabular}

increase in all three types of colonies compared to the pretreatment marrow. Addition of the patient's pretreatment plasma completely inhibited the growth of CFU-C-derived colonies (Fig. 2). On the other hand, two patient plasma samples obtained after B 12 theapy and the control plasma showed no effect (Fig. 2). As shown in Table 2, the plasma inhibitory activities were also seen on the erythroid colony growth. Furthermore, the inhibition was dem. onstrated on both patient and control marrow cells (Table 2). In the light of these data, we tested the direct effect of MMA on the cell viability and proliferation in vitro. There was no significant difference in the recovery and viability of cells between MMAincubated cells and control cells when the cells were incubated overnight (16 to $18 \mathrm{hr}$ ). In a next series of experiments, marrow cells were cultured with varying concentrations of MMA. Percentage inhibition by MMA was calculated by using the formula:

No. of colonies formed without MMA

$$
\frac{- \text { No. of colonies formed with MMA }}{\text { No. of colonies formed without MMA }} \times 100
$$

When increasing concentrations of MMA were added to plates seeded wth control marrow cells, a concentration-dependent inhibition was observed (Fig. 3). This was most evident in the growth of CFU-C derived colonies (Fig. 3a). Although similar inhibition was also observed in the erythroid colony growth, the degree of the inhibitory effect on CFU-E and BFU-E growth varied markedly from specimen to specimen (Fig. 3, b and c). Furthermore, within the same specimen, different types of stem cells showed varying susceptibility to MMA inhibition. In specimen 3,98\% of CFU-C was inhibited by a MMA concentration of $35 \mathrm{mg} / \mathrm{dl}$. The same MMA concentration, on the other hand, showed only $36 \%$ inhibition of CFU-E and $17 \%$ inhibition of BFU-E growth. The opposite was true in specimen 1 , in which CFU-E inhibition was greater than CFU-C inhibition.

\section{DISCUSSION}

MMA-emia is an inherited disorder caused by deficiency of either one of two enzymes necessary for the conversion of Dmethylmalonyl CoA to succinyl CoA $(14,19)$, methylmalonyl CoA racemase, and methylmalonyl CoA mutase (MM CoA mutase). The defect in MM CoA mutase activity may result from an abnormality of mutase itself or from defective synthesis of the cofactor adenosylcobalamin. Our patient did not appear to have a deficiency in either methylmalonyl CoA racemase or mutase because he responded well to vitamin B 12 treatment. Thus, it is likely that this patient had a defect in the synthesis of cofactor adenosylcobalamin. Synthesis of adenosylcobalamin from hydroxycobalamin requires several biochemical steps (15). A defect at the early steps of cofactor synthesis results in deficiency in both methyl- and adenosylcobalamin. Patients with this type of defect

Fig. 3. Effect of methylmalonic acid directly added to culture plates. The percent inhibition was calculated by the formula described in the text. $a$, concentration-dependent inhibition by CFU.C-derived colonies; $b$ and $c$, concentration-dependent inhibition by CFU-C- and BFU-E-derived colonies, respectively.

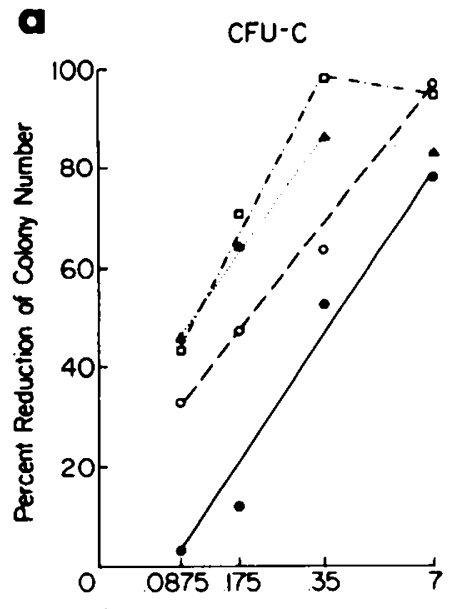

MMA concentration $(\mathrm{mg} / \mathrm{ml})$

$\longrightarrow$ specimen 1 $\infty-\infty$ specimen 2 a.-. specimen 3
. specimen 5
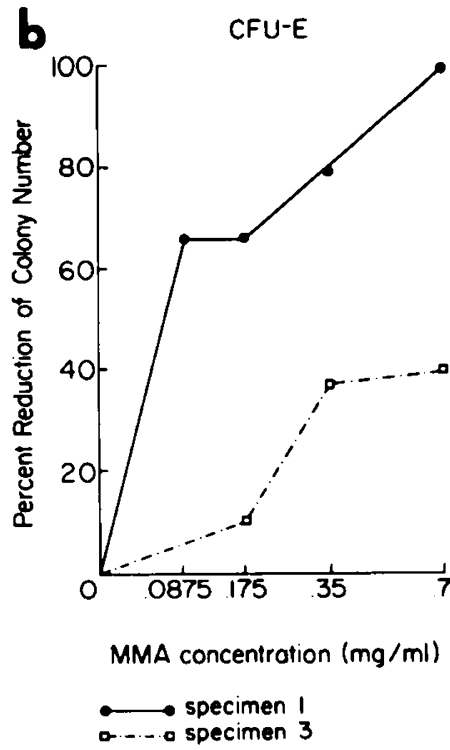

C BFU-E

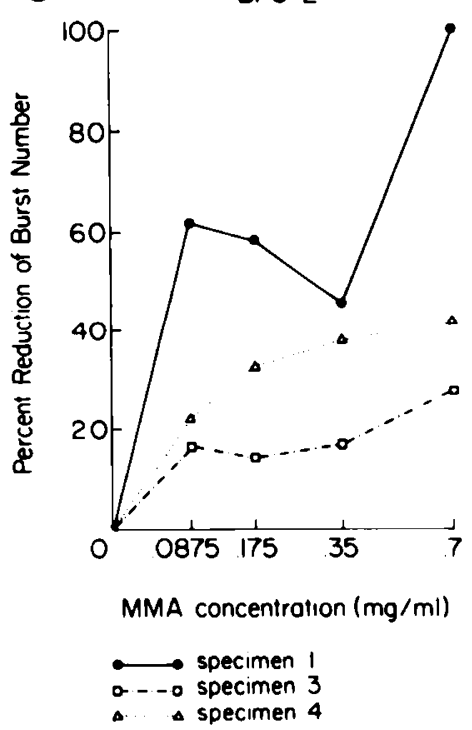


showed increased urinary homocystine excretion and decreased plasma methionine and megaloblastic anemia (6). The normal plasma methionine and urinary homocystine levels in our patient indicate intact methylcobalamin synthesis. Mild-to-moderate excretion of urinary methylmalonate is also seen in patients with primary B 12 deficiency $(3,5)$, but they had megaloblastic anemia which was not seen in our patient. The abnormality in our patient, therefore, appears to reside in the final conversion steps of hydroxycobalamin to adenosylcobalamin.

Neutropenia and thrombopenia have been observed in MMAemia $(9,14,18,19)$, but there is to our knowledge no description of a case with pancytopenia. The pancytopenia in our patient was due to depressed hemopoiesis in the marrow. We studied the pathogenesis of the bone marrow hypoplasia using the in vitro hemopoietic cell culture technique. The technique enabled us to examine the effects of putative toxic substances such as MMA on the proliferation and maturation of committed myeloid and erythroid stem cells. The semisolid methylcellulose immobilizes the proliferating cells. Thus, each aggregate of cells called "colony" derives from a single precursor cell. The number of colonies, therefore, represents the number of viable precursor cells that were present at the beginning of culture. Marrow cells aspirated during the period of pancytopenia before treatment showed a reduced number of CFU-E- and BFU-E-derived colonies as compared with the control marrow cells, but they were by no means absent. In contrast, culture of marrows from patients with aplastic anemia usually resulted in either none or very little colony growth $(4,7,11)$. This may imply that marrow stem cells were relatively well preserved in this patient in contrast to the patients with aplastic anemia. Our study showed that the pretherapy but not the posttherapy plasma contained a substance or substances capable of inhibiting growth of myeloid and erythroid precursors. These in vitro findings are consistent with the clinical picture of pancytopenia. However, the inhibitory effects of the patient's plasma could have been nonspecific. A variety of nonspecific serum or plasma inhibitors has been described. These include very low density lipoprotein (20), interferon (2), and prostaglandin E $(12,17)$. Evidence that the inhibitory activities found in the patient's plasma was due to the high concentration of MMA was obtained by the culture experiments in which several MMA concentrations were directly added to the culture dishes. In these studies, CFU-C-, CFU-E-, and BFU-E-derived colonies formed by control marrow cells was inhibited by MMA in a dose-dependent fashion. On the other hand, overnight incubation of cells in MMA (70 mg/dl) did not affect the cell viability. These observations suggest that MMA within the concentration used here is not immediately cytotoxic. Thus, the MMA inhibitory activities may be directed at the proliferation of cells.

The MMA concentrations at which in vitro inhibition of colony formation occurred were within the range reported in patients with MMA-emia (19). Plasma MMA levels were not determined in our patient, but it can be assumed to be within the range seen in other patients because the MMA excretion of our patient was comparable. Although MMA is the major metabolite excreted in MMA-emia, other organic acids may appear in the urine $(9,19)$. It is possible, therefore, that these substances also play a role in the pathogenesis of marrow hypoplasia. Indeed, preliminary marrow culture studies with propionic acid, which is also known to be increased in patients with MMA-emia (19), demonstrated inhibitory activities on CFU-C by this substance in a dose-dependent fashion. The $50 \%$ inhibition of colony growth was achieved at about $1 \mathrm{mmole} / \mathrm{liter}$ of propionic acid (unpublished data). However, because our patient did not have an increased propionic acid level, it is doubtful that this substance played a significant role in hemopoiesis inhibition in our case. Another heritable metabolic disorder known to be associated with pancytopenia (13) is isovaleric acidemia. Our preliminary studies showed that isovaleric acid was also capable of inhibiting the growth of CFU-C (50\% inhibition at about 2 mmoles/liter) and of CFU-E and BFU-E (50\% inhibition of at about $0.35 \mathrm{mmole} / \mathrm{liter}$ ). Whether other organic acids also inhibit in vitro marrow cell growth given in enough concentrations remains to be determined. Mechanism of inhibition by MMA as well as of other organic acids remain to be elucidated.

\section{REFERENCES AND NOTES}

1. Alexrad, A. A., McLeod, D. L., Shreeve, M. M., and Heath, D. S. Properties of cells that produce erythrocytic colonies in vitro. In: W. A. Robinson: Hemopoiesis in Culture. Second International Workshop, p. 226 (Department of Health, Education, and Welfare, Publication 74-205, 1974).

2. Balkwill, F. R., and Oiiver, R. T. D.: Growth inhibitory effects of interferon on normal and malignant human hemopoietic cells. Int. J. Cancer, 20: 500 (1977).

3. Barness, L. Young, D. Nellman, W., Kahn, S., and Williams, W. Methylmalonate excretion in a patient with pernicious anemia. N. Engl. J. Med., 208: 144 (1963).

4. Chu. J. Y., Ho, J. E., McElfresh. A. E., and Monteleone, P.: Granulopoiesis and bone marrow scan in Fanconi's aplastic anemia. (Abstract) In: Proceedings of 19th Annual Meeting of American Society of Hematology. p. 114 (1976).

5. Cox, E., and White, A.: Methylmalonic acid excretion: an index of Vitamin B12 deficiency. Lancet, 2: 854 (1962).

6. Dillon, M. J., England, J. M., Gompertz, D., Goodey, P. A., Grant, D. B. Hussein, H. A., Linnell, J. C., Mathews D. M., Mudd, S. H., Newns, G. H. Seakins, J. W. T., Uhlendorf, B. W., and Wise, I. J.: Mental retardation. megaloblastic anemia, methylmalonic acidemia and abnormal homocysteine metabolism due to an error in vitamin B12 metabolism. Clin. Sci. Mol. Med. 47: 43 (1974).

7. Goldberg. J.. Nelson, S. A.: Colony forming and colony stimulating activity in adult aplastic anemia. In: Proceedings of 19th Annual Meeting of American Society of Hematology. p. 115 (1976).

8. Goodman, S. I., Moe, P. G., Hammond, K. B., Mudd, S. H., and Uhlendorf, B. W.: Homocystinuria with methylmalonic aciduria. Two cases in a sib. Biochem Med., 4: 500 (1970).

9. Hsia, Y., Lilljequist, A., and Rosenberg, L.: Vitamin B12-dependent methylmalonic aciduria: amino acid toxicity, long chain ketonuria, and protective effect of vitamin B12. Pediatrics, 46: 497 (1970).

10. Inoue, S., and Ottenbreit, M. J.: Heterogeneity of human colony forming cells. Blood, 5l: 195 (1978).

11. Inoue, S., Ravindranath, Y.. Lusher, J. M., and Itoh. T.: Absence of inhibitory cells from patients with aplastic anemia or transient erythroblastopenia of childhood on the in vitro growth of erythroid colonies. Acta Haematol. Jpn. 43: 76 (1980).

12. Kurland, J., and Moore, M. A. S.: The regulatory role of the macrophage in normal and neoplastic hemopoiesis. In: S. J. Baum, G. D. Ledney: Experimental Hematology Today. p. 51 (Springer-Verlag. New York, 1977).

13. Levy, H. L., Erickson, A. M., Lott, I. T., and Kiertz, D. J.: Isovaleric acidemia results of family study and dietary treatment. Pediatrics, 52: 83 (1973).

14. Maoney, M. J.: Organic acidemias. Clin. Perinatol.. 3: 61 (1976).

15. Maoney, M. J., and Rosenberg, L. E.: Inherited defects of B12 metabolism. Am. J. Med., $48: 584$ (1970)

16. Mudd, S. H., Levy, H. L., and Abeles, R. H.: A derangement in B 12 metabolism leading to homocystinemia, cystathioninemia and methylmalonic acidemia Biochem. Biophys. Res. Commun., 35: 121 (1969).

17. Neal, W. A., Lewis, J. P., Lutcher, C. L., Welch, E. T., Ozawa, T. Moore, R. R. and Wright, C. S.: Inhibition of erythropoiesis by components from human plasma and urine. Blood (Astract), 52 (Suppl. 1): (1978).

18. Nyhan, W., Ando. T., and Rasmussen, K.: Ketotic hyperglycinaemia. In: J. Stern, C. Toothill: Organic Acidemias. p. I (Churchill Livingstone, Edinburgh, Eng land. 1972).

19. Rosenberg, L.: Disorders of propionate, methylmalonate, and Vitamin B12 metabolism. In: J. Stanbury, J. Wyngaarden, D. Fredrickson: The Metabolic Basis of Inherited Diseases. p. 411 (McGraw-Hill Book Co., New York, 1978).

20. Zucker, S., Glucksman, M. J., Lysik, R. M., Skowron, G., and Beck, V. A. Biological and chemical characterization of very low density lipoprotein (VLDL) inhibitor of hematopoiesis. Blood (Abstract). 52 (Suppl. I): 219 (1978)

21. Requests for reprints should be addressed to: Susumu Inoue, M.D., Children's Hospital of Michigan, 3901 Beaubien Boulevard, Detroit, MI 48201 (USA).

22. This research was supported in part by a grant from Children's Leukemia Foundation of Michigan and Bonnie Baker Fund.

23. Received for publication January 21, 1980

24. Accepted for publication April 11, 1980. 